\title{
Viability of Multi-Specialty Dental Center in Bacolod City
}

\author{
Jasmine Joyce G. Mendez ${ }^{1}$ and Rizalie N.E. Mibato ${ }^{2}$ \\ 1,2University of Negros Occidental-Recoletos, Bacolod City, Philippines
}

\section{Article history \\ Submitted: 25 June 2020 \\ Revised: 25 October 2020 \\ Accepted: 10 November 2020}

\section{Keywords}

Hospital Administration

Multi-Specialty Dental

Viability

Descriptive Research

Bacolod City
Introduction. A Multi-Specialty Dental Center (MSDC) is one in which dentists share facilities, administration, income and expenses, support staff, and equipment. It is a single practice entity that provides general dentistry services in collaboration with the provision of one or more dental specialties. Moreover, dentists can specialize in related dental practices or offer a wide range of specialties. This business is relatively stable as it is a growing source of revenue. The primary purpose of a multi-specialty dental clinic is to serve all the needs of patients in one convenient location. Dental specialists can consult with each other and provide tests and radiological exams under one roof. Having a group of experts, dental professionals who can perform together to surpass a patient's dental or aesthetic objectives is an advantage. It is also essential to address a potential challenge within the multi-specialty dental facility.

Methods. Descriptive research utilizing a researcher-made survey questionnaire was used to determine the viability of the Multi-Specialty Dental Center, in terms of management, marketing, technical, financial (profitability, liquidity, and solvency) and socio-economic aspects, challenges and opportunities of the center as well as its marketability utilizing the elements of the marketing mix. Through purposive sampling, one hundred thirty-seven (137) respondents were selected to participate in the survey. The data were gathered using a researcher-made instrument. Descriptive statistics were employed using mean and standard deviation to determine the degree of viability. For challenges and opportunities, frequency count and percentage distribution were used to describe "what exists" concerning the variables. A three-year projected financial ratios analysis was employed to evaluate the financial performance of the center in terms of profitability, liquidity, and solvency.

Results. The overall findings of the study revealed that the degree of viability in terms of management, marketing, technical, financial, and socio-economic aspects is highly viable. As to the management aspect, efficiency is the issue in health care centers and dentistry clinics. As to the marketing aspect, a dental center ambiance promotes a positive experience for the patient; hence, for technical facilities, patients prefer ergonomically designed dental facilities and equipment. On the financial performance, gross profit ratios show the adequacy of gross margin to cover operating expenses. The net profit margin and the owner's equity increase are good indicators that the business is performing well. The center is in a better position to meet its short-term and long-term obligations. It may be predicted that the center may gain full ownership of the building, thereby increasing its fixed assets and reducing its long-term liabilities. The socio-economic aspect is highly viable. The study revealed that the dental entrepreneur has strong international, national, and local affiliations. The paradigm shift of primary dental care to comprehensive dental care poses an opportunity for MSDC.

Conclusion. The Multi-Specialty Dental Center is a highly viable business being the pioneer in the city. In summary, MSDC, as a firm, is growing and may have the capability of expanding in the future. The study may serve as a baseline in the formulation of research in line with other dental health-related businesses and the impact of the COVID-19 pandemic to increase revenue in the dental profession. During this pandemic, MSDC may have the edge over the traditional dental clinics because MSDC has its sterilization room, doffing and donning room, and operatory rooms with negative pressure to control the spread of infections. It also uses operatory decontamination equipment, operatory disinfection, and aerosol control practices. The center may also hire dental nurses, well-trained dental assistants and administrative staff, and highly skilled dentist/dental consultants. MSDC has its own dental laboratory to cater to all laboratory works in the center. 
Practical Value of the Paper: The output of the study is a Feasibility Study for the Multi-Specialty Dental Center. This research further contributes to the dental industry in the province being the pioneer in the specialty facility and the leader in the industry. It may provide information about its financial viability of upgrading the traditional dental clinics into a multi-specialty dental center.

\section{References}

Akrami, N., Taghavi Bayat, J., Huggare, J., Mohlin, B. (2017). Determinants of Orthodontic Treatment Need and Demand: A Cross-sectional Path Model Study. European Journal of Orthodontics.

Alaghemandan, H., Yarmohammadian, M. H., Khorasani, E., \& Rezaee, S. (2014). Efficiency Improvement of Dentistry Clinics: Introducing an Intervening Package for Dentistry Clinics, Isfahan, Iran. International Journal of Preventive Medicine, 5(2), 176.

Bommireddy, V. S., Pachava, S., Ravoori, S., Sanikommu, S., Talluri, D., \& Vinnakota, N. R. (2014). Socio-economic Status, Needs, and Utilization of Dental Services among Rural Adults in a Primary Health Center Area in Southern India. Journal of International Oral Health: JIOH, 6(6), 56.

Dhanore, P., Shaik, A., \& Ramtekkar, P. (2016). Dental Clinic Management System-A New Approach. International Journal of Science, Engineering and Computer Technology, 6(5), 176.

González-Robledo, L. M., González-Robledo, M. C., \& Nigenda, G. (2012). Dentist Education and Labour Market in Mexico: Elements for Policy Definition. Human Resources for Health, 10(1), 31.

Kalenderian, E., Maramaldi, P., Kim, S., Etolue, J., McClellan, L., Simmons, K., Yansane, A., White, JM., Walji, MF., \& Ramoni, R. B. (2016). Strategic Shift to a Diagnostic Model of Care in a Multi-site Group Dental Practice. International Journal of Dentistry and Oral Health, 2(4).

Krois, Samek, \& Schwendicke (2020). Artificial Intelligence in Dentistry; Chances and Challenges. Journal of Dental Research.

Masic, F. (2012). Information Systems in Dentistry. Acta Informatica Medica, 20(1), 47.

Palència, L., Espelt, A., Cornejo-Ovalle, M., \& Borrell, C. (2014). Socio-economic Inequalities in the Use of Dental Care Services in Europe: What is the Role of Public Coverage? Community Dentistry and Oral Epidemiology, 42(2), 97-105.

Panigrahi, C. M. A. (2014). Relationship of Working Capital with Liquidity, Profitability, and Solvency: A Case Study of ACC Limited. Asian Journal of Management Research, 4(2), 308-322.

Pornel, Balinas, \& Saldana (2011). Nearest-Integer Responses from Normally Distributed Opinion Model for Likert Scale. University of the Philippines in the Visayas.

\section{Correspondence:}

Jasmine Joyce G. Mendez [jpgm0203@gmail.com]

https://orcid.org/0000-0002-2585-8148 